\title{
LA DEPURACIÓN FRANQUISTA DEL MAGISTERIO PÚBLICO. UN ESTADO DE LA CUESTIÓN
}

por

\author{
FRANCISCO MORENTE VALERO \\ Universidad Autónoma de Barcelona
}

RESUMEN: La publicación en los últimos años de una serie de trabajos sobre la depuración del Magisterio durante la guerra civil y la inmediata postguerra invita a realizar un primer balance de la cuestión que intente conjugar los análisis cuantitativos y los cualitativos, al tiempo que muestre las semejanzas y diferencias de los procesos de depuración seguidos en las distintas provincias españolas hasta abora estudiadas, $y$ permita, a partir de los datos parciales ya sólidamente establecidos, hacer una estimación del alcance real que la depuración del Magisterio tuvo en el conjunto español. Así, en el artículo se desvelan los fundamentos ideológicos de la depuración, se explican sus mecanismos y se realiza una estimación sobre los resultados globales de la misma; igualmente, se muestra el carácter inquisitorial que tuvo el proceso, la bomogeneidad del mismo en cuanto a la legislación aplicada y los criterios seguidos en su desarrollo, y se enmarca la acción represiva sobre el Magisterio en el conjunto de la politica educativa del régimen y en su obsesión por liquidar cualquier resto de las reformas educativas de la República.

Palabras clave: España. Guerra Civil. Dictadura franquista. Represión. Depuración del Magisterio. Política educativa.

ABSTRACT: The recent publication of several works on the ideological purge of teachers during and after the Civil War enables us to undertake an initial evaluation and integration of quantitative and qualitative analyses. At the same time, it provides us with parallel studies that show similarities and differences in the purges carried out in several Spanish provinces. All of this in turn allows us to estimate, based on incomplete but well-established data, the overall magnitude of the purge. In this article, the ideological foundations of the purge and its mechanisms are analysed and discussed in depth. In addition, I present an account of its global results and a full explanation of the inquisitorial character with which the whole process was

Hispania, LXI/2, núm. 208 (2001) 661-688 
impregnated. The bomogeneity of the process in terms of legislation and the criteria established throughout are presented and thoroughly discussed as well. Finally, the repressive action exerted on teachers is framed within the educational policy of Franco's regime and its obsession with eliminating any form of educational reform left from the Republic.

KEY WORDS: Spain. Civil War. Franco's dictatorship. Repression. Teachers' purge. Educational policy.

La represión franquista durante la guerra civil y la inmediata postguerra ha sido objeto en los últimos años de una especial atención por parte de los historiadores y ha dado lugar a un ingente número de monografías, especialmente por lo que hace a la violencia física (reglada o no), de forma que poco a poco va siendo posible realizar un cómputo bastante aproximado de la misma. En una obra relativamente reciente, Alberto Reig hacía un primer balance de esta producción historiográfica comparando las cifras de ejecutados por el bando franquista que de ella se derivan con las que había aportado el estudio de Ramón Salas Larrazábal, adelantado de estas cuestiones ${ }^{1}$. Del cotejo de las cifras aportadas por Salas para 15 provincias españolas con las resultantes de 15 estudios monográficos sobre las mismas se desprendía que el trabajo de aquél había recogido, como mucho, el $50 \%$ de los asesinatos y ejecuciones realmente cometidos por el bando nacional, con lo que el aséptico empate técnico decretado por Salas entre la represión franquista y la republicana (y que tan bien se avenía con la idea del «todos fuimos culpables» y con el «borrón y cuenta nueva» que caracterizó a la transición política) se convertía en una abrumadora superioridad de los franquistas a la hora de liquidar a los adversarios ${ }^{2}$.

Más recientemente, la publicación de una obra colectiva sobre la represión durante la guerra y la postguerra ha venido a confirmar plenamente lo que ya había apuntado Reig Tapia ${ }^{3}$. Así, mientras la represión republicana en 22 provincias estudiadas (prácticamente la totalidad del territorio republicano durante la guerra) arroja una cifra de 37.843 víctimas, la franquista (de guerra y postguerra) en 24 provincias de las que hay estudios completos sitúa el número de víctimas en 72.527 (cifra que hay que considerar como un mínimo, pues hay certeza de muertes que no dejaron ningún tipo de rastro en los registros; así, por ejemplo, en Granada se han certificado 5.048 muertos, pero el autor

1 ReIG TAPIA, Alberto: Franco "Caudillo»: mito y realidad, Madrid 1995. SAlas LARRAZÁBAL, Ramón, Pérdidas de la guerra, Barcelona 1977.

2 Los datos corresponden a las provincias de Alicante, Asturias, Córdoba, Girona, Huelva, Granada, Huesca, Jaén, La Rioja, Málaga, Navarra, Sevilla, Soria, Teruel y Zaragoza; en la obra de Salas, la cifra de ejecutados en las mismas es de 23.791; las quince monografías recogidas por Reig sitúan ese número en 47.938; Reig, además, confirma esa tendencia con el caso de Valencia (3.973 ejecutados según Salas, 6.087 según Vicente Gabarda); cfr. REIG TAPIA, Alberto, op. cit., págs. 207-209.

3 Julı́, Santos (coord.): Víctimas de la guerra civil, Madrid 1999. 
del estudio provincial estima que la cifra total debió de superar los 12.000). Hay datos, aún parciales, de cinco provincias más en las que ya se han establecido otras 8.568 muertes; así pues, existe constancia de más de 81.000 asesinados y ejecutados por los franquistas en 29 provincias, y quedan aún más de 20 por estudiar, entre ellas las gallegas y las de Castilla-León, donde hay evidencias de que la represión fue feroz $z^{4}$.

En definitiva, las tendencias son bien claras: a) nada de empate técnico entre la represión de ambos bandos (ni aun olvidándonos de la represión de postguerra; b) las cifras de la represión republicana aportadas por Salas se han de revisar a la baja, y seguramente no superaron las 50.000 ; y c) las cifras de la represión franquista se han de elevar considerablemente en relación con las consideradas buenas por Salas, y probablemente se situarán en torno a las 140.000 , de las que casi 50.000 corresponderán a las ejecuciones de postguerras.

A estas alturas es difícilmente discutible que la represión constituyó un elemento esencial en la instauración y mantenimiento del régimen franquista. No fue simplemente una consecuencia de la situación bélica que vivía el país (como en gran medida ocurrió en el lado republicano), sino un instrumento conscientemente utilizado para la conquista del poder y, lo que es más importante, para mantenerse indefinidamente en el mismo. Existe un amplio consenso a la hora de aceptar que la represión ejercida por el Nuevo Estado durante sus primeros años superó en mucho la llevada a cabo por otros regímenes fascistas (especialmente si la comparación se realiza con Italia) ${ }^{6}$, como consecuencia de la diferente forma de asalto al Estado que se siguió en cada país; en ese sentido, la guerra civil constituye, evidentemente, un elemento determinante. Ahora bien, a partir de 1943, momento en que todos los estudios detectan una inflexión en la violencia represora, el régimen franquista va a seguir una política represiva absolutamente homologable a la de los fascismos italiano y alemán, y que podría sintentizarse en los siguientes rasgos: articulación de un potente aparato policíaco, ejercicio selectivo de la represión, concentrándola sobre deteminados sectores sociales y grupos políticos, extensión de lo punible desde las conductas puramente políticas a los aspectos más íntimos de la vida

4 lbid., págs. 411-412.

5 La tozudez de los hechos ha obligado a que incluso quienes en su momento dieron por buenos los datos de Salas (al menos para las ejecuciones de postguerra) reconozcan ahora que éstos deben considerarse como un mínimo, y que una cifra que doble la ofrecida por el general no es en absoluto descabellada; cfr. TuSELl, Javier: La dictadura de Franco, Madrid 1988, pág. 226, y TUSELL, Javier: «Los muertos de Franco»: El País, 22 de diciembre de 1997, pág. 13. Aunque también es verdad que sigue habiendo quien se resiste a aceptar la evidencia; así, Payne, todavía en 1993, seguía considerando los estudios de Salas como los mejores (eso sí, sin citar ningún otro con el que pudiera establecerse la comparación); cfr. PAYNE, Stanley G, Franco. El perfil de la historia, Madrid 1993 , págs. 82-84.

6 Véase al respecto la opinión de Silvio Lanaro en BARBAGALLO, Francesco et al., Franquisme. Sobre resistència $i$ consens a Catalunya (1938-1959), Barcelona 1990, págs. 43-44; igualmente TuSELL, Javier: La dictadura..., op. cit., pág. 340. 
cotidiana, y creación de un ambiente de control político e ideológico generalizado que produce un efecto no sólo intimidatorio sino también paralizante a través de la extensión del sentimiento de que nadie está a salvo de la acción represora del Estado?.

La extraordinaria duración de la dictadura de Franco difícilmente puede explicarse sin atender a todo lo anterior. Sin menospreciar la importancia de los apoyos sociales que el régimen pudo concitar, sería ingenuo concluir que la más o menos extendida aceptación de aquél era simplemente el resultado de la propaganda, la socialización política conseguida a través del sistema educativo (y de otras instituciones) o de la evidencia de los logros del régimen. Que estos (y otros) factores ayudaron a crear una situación de cierta pasividad social (relativa por otra parte) es indudable; pero no lo es menos que en igual o mayor medida contribuyó a ello la persistente violencia institucional ejercida por el régimen desde sus orígenes ${ }^{8}$.

Esa violencia, por otra parte, no se manifestaba únicamente mediante el encarcelamiento y las ejecuciones, sino que adoptaba también formas no por menos sangrientas menos efectivas a la hora de conseguir la neutralización de los adversarios del régimen; así, las multas, las listas negras, los efectos de tener antecedentes penales, etc. eran instrumentos eficaces de lo que podríamos llamar una represión de baja intensidad. Junto a ellos, las represalias de tipo profesional fueron a lo largo de la vida del régimen, pero muy especialmente en los inicios del mismo, una forma eficacísima de sancionar desafectos y paralizar a los no adictos (así como de premiar a los incondicionales mediante las plazas vacantes que dejaban los represaliados). Estas depuraciones político-profesionales, que afectaron muy especialmente a la administración pública, fueron un instrumento no sólo para la sanción de las ideas y conductas consideradas inconvenientes en el nuevo régimen, sino también, muy especialmente, para la adecuación del perfil ideológico de los funcionarios y trabajadores al servicio del Estado a las directrices que regían en la España de Franco. En este sentido, su estudio se revela como una forma especialmente enriquecedora de aproximarse a la naturaleza del régimen franquista, pues conociendo los elementos sobre los que se basaron los distintos

7 Véanse, entre otros, Ruiz CARnicer, Miguel Angel y CenARro Lagunas, Angela: «La «represión política» y sus formas: fuentes y métodos de estudio»: Metodología de la Investigación Científica sobre Fuentes Aragonesas 6 (s.a.) 250-252, y SOLÉ I SABATÉ, Josep M.: «La justicia catalana franquista y sus fuentes»: SÁNCHEZ, Isidro, ORTIZ, Manuel y RuIZ, David: España franquista.Causa general y actitudes sociales ante la Dictadura, Universidad de Castilla-La Mancha 1993, pág. 87.

8 Para un análisis de los distintos factores que condicionaron las actitudes de diversos sectores sociales ante el franquismo, véanse RuQUER, Borja de: «Rebuig, passivitat i suport. Actituds polítiques catalanes davant el primer franquisme (1939-1950)»: BARBAGALLO, Francesco et al., op. cit., págs. 179-193, BERNAL, Antonio-Miguel, «Resignación de los campesinos andaluces: la resistencia pasiva durante el franquismo», SÁNCHEZ, Isidro, ORTIZ, Manuel y RUIZ, David: op. cit., págs. 152153, y Molinero, Carme y Ysàs, Pere: El règim franquista. Feixisme, modernització $i$ consens, Vic 1992, págs. 73-74.

Hispania, LXI/2, núm. 208 (2001) 661-688 
procesos depuradores puestos en marcha desde el inicio mismo de la guerra civil, sabremos mucho más sobre las bases políticas, ideológicas, filosóficas e incluso morales sobre las que se quiso sostener aquel régimen.

\section{LA DEPURACIÓN DEL MAGISTERIO PÚBLICO}

La idea de que fue el Magisterio el cuerpo de la administración que sufrió una persecución más atroz por parte del régimen franquista ha estado siempre ampliamente extendida, y no sólo entre los historiadores sino también en el imaginario popular. La razón de ello estriba en que habían sido los mismos publicistas de la causa nacional, así como prominentes autoridades franquistas, los que se habían encargado de repetir hasta la extenuación que los intelectuales, los profesores y los maestros eran los principales responsables de la, para ellos, degradación espiritual que había conducido a España hasta el despeñadero de la guerra civil ${ }^{2}$. Así las cosas, no ha de extrañar que historiadores y escritores antifranquistas diesen por buena tal impresión y la llevaran hasta extremos a todas luces exagerados, como cuando Max Gallo afirmaba que en la España franquista el $50 \%$ de los maestros habían sido fusilados ${ }^{10}$.

Hoy en día se dan las circunstancias adecuadas para un análisis más fundamentado de toda esta cuestión. En los últimos años han ido apareciendo una serie de trabajos, de diverso calado, calidad y fiabilidad, que permiten si no zanjar definitivamente la cuestión, sí establecer los cimientos de una interpre-

9 Así, por ejemplo, el futuro ministro de Educación de Franco, Pedro Sainz Rodríguez, afirmaba que la escuela republicana «era la más fuerte empresa de embrutecimiento colectivo que haya podido caer sobre la conciencia humana» [cit. en NAvARro, Ramón: L'educació a Catalunya durant la Generalitat 1931-1939, Barcelona 1979, pág. 151]. Otro ministro de Educación, José Ibáñez Martín, comentando en 1943 la depuración de maestros, afirmaba: "Como en un organismo vivo tiranizado por el mal, España tuvo que diseccionar zonas excepcionales de su masa vital. Al Magisterio afectó quizá con inusitada fuerza esta tarea de purificación. Pero un supremo interés religioso y un soberano interés nacional lo exigían así» [IBÁÑEz MARTín, José: La escuela bajo el signo de Franco (Discurso de clausura del Primer Congreso Nacional del S.E.M.), Madrid 1943, pág. 8]. Quizás la quintaesencia de esa idea esté representada en el libro de Enrique SUÑER, vicepresidente de la Comisión de Cultura y Enseñanza de la Junta Técnica del Estado, Los intelectuales y la tragedia española, Burgos 1937, acabado ejemplo de interpretación paranoica y conspirativa de la historia.

10 Gallo, Max, Historia de la España franquista, París 1971, pág. 92; en otro lugar, Gallo asegura que los maestros fusilados eran 6.000 (p. 66), lo que se compadece mal con la afirmación anterior, pues es evidente que la plantilla del Magisterio Nacional era muy superior a los doce mil enseñantes. En este ejemplo, la dificultad para acceder a las fuentes (o las propias necesidades del combate antifranquista) puede justificar el abultado error; no parece de recibo, sin embargo, que en fechas mucho más recientes se sigan realizando afirmaciones del todo inexactas y exageradas que no pueden ser más que fruto del desconocimiento o de la mala fe: así, F. Ferrer i Gironès cuando afirma que «No cal dir que els mestres que varen obtenir el títol durant la República varen ser destituïts en llur majoria» [FERRER GIRONÈs, Francesc: La persecució política de la llengua catalana, Barcelona 1993, $2^{\mathrm{a}}$ ed., pág. 184$]$. 
tación de la misma que futuras investigaciones monográficas difícilmente alterarán en lo sustancial. De hecho, por lo que hace a la explicación de la mecánica del proceso depurador, sus fundamentos legales, su aplicación práctica, sus bases ideológicas y sus fines, difícilmente se podrá añadir nada nuevo a lo ya explicado en algunos de los estudios fundamentales sobre este asunto ${ }^{11}$. Otra cosa es el aspecto meramente cuantitativo de la depuración, que no será posible desvelar del todo hasta que se complete el estudio de la depuración en todas y cada una de las provincias españolas ${ }^{12}$, lo que, como es obvio, puede llevar todavía bastantes años. Pese a todo, con los estudios provinciales ya disponibles se puede realizar una aproximación al resultado final de la depuración que, con toda seguridad, y con los inevitables márgenes de error, no se alejará demasiado de lo que en realidad ocurrió.

\section{Las fuentes para el estudio de la depuración del Magisterio, y sus limita- ciones}

Cuando se inició el proceso depurador, en las primeras semanas de la guerra civil, las sanciones que recaían sobre los maestros eran publicadas en el Boletín Oficial de la Junta de Defensa Nacional de España, y desde octubre de 1936 en el Boletín Oficial del Estado (BOE). Pronto se vio que la envergadura de la depuración del Magisterio era mucho mayor de lo que sus impulsores inicialmente habían previsto, y se constató que la publicación en el $B O E$ de las resoluciones de los expedientes podía llevar al colapso de éste, por lo que se acordó que, en lo sucesivo, dichas resoluciones se publicasen en el Boletín Oficial de la Provincia $(B O P)$ correspondiente ${ }^{13}$. Así pues, estas tres publicaciones oficiales constituyen una fuente indispensable para el estudio cuantitativo de la depuración del Ma-

11 Muy especialmente, CRESPO Redondo, Jesús et al.: Purga de maestros en la guerra civil. La depuración del magisterio nacional de la provincia de Burgos, Valladolid 1987; OsTOLAZA ESNAL, Maitane: El garrote de la depuración. Maestros vascos en la guerra civil y el primer franquismo (1936-1945), Donostia-San Sebastián 1996; MORENTE VALERO, Francisco: Tradición y represión. La depuración del magisterio de Barcelona (1939-1942), Barcelona 1996; del mismo autor, La escuela y el Estado Nuevo. La depuración del Magisterio Nacional (1936-1943), Valladolid 1997; y FERNÁNDEZ SORIA, Juan Manuel y $\mathrm{M}^{\mathrm{a}}$ del Carmen AGULLó DíAz: Maestros bajo el Franquismo. La depuración del Magisterio Valenciano (1939-1944), Valencia 1999.

12 La depuración del Magisterio fue encargada a comisiones de ámbito provincial, formadas cada una de ellas por un director de Instituto de Bachillerato (que la presidía), un inspector de Enseñanza Primaria, el presidente de la Asociación católica de padres de familia de la provincia y «dos personas de máximo arragio y solvencia moral y técnica» (Decreto de 8 de noviembre de 1936, Boletín Oficial del Estado del 11); bastante más adelante, una Orden ministerial añadió dos nuevos miembros a las comisiones, designados a propuesta de la respectiva Jefatura provincial de Falange Española Tradicionalista y de las JONS (BOE del 8 de noviembre de 1939).

13 Orden de 27 de noviembre de 1937 (BOE del 1 de diciembre).

Hispania, LXI/2, núm. 208 (2001) 661-688 
gisterio ${ }^{14}$, pero son, lamentablemente, insuficientes: por una parte, y sin que sea posible explicar los motivos, no todas las resoluciones de expedientes fueron publicadas en ellas (aunque sí la inmensa mayoría); por otra, apenas aparecen resoluciones de expedientes de revisión, aspecto que no se puede dejar de lado si se quiere valorar en sus justos términos los efectos cuantitativos de la represión del Magisterio. Los primeros estudios de la depuración (pero también otros realizados desde entonces) han tenido como fuente prácticamente exclusiva estas publicaciones oficiales ${ }^{15}$, lo que limita su validez en un doble sentido; por un lado, las citadas carencias en cuanto a la información puramente cuantitativa; en segundo lugar, por el hecho de que en las publicaciones oficiales sólo se informa del nombre del maestro o maestra, de la resolución definitiva de su expediente y, en ocasiones, de la localidad donde ejercía y de la categoría profesional que ostentaba, lo que impide hacer cualquier tipo de estudio sobre los aspectos cualitativos de la depuración.

La documentación fundamental para el estudio de la depuración es, obviamente, la generada por las comisiones depuradoras: las declaraciones juradas de los expedientados, los informes de autoridades y particulares, las denuncias, los papeles internos de la propia comisión y, finalmente, su propuesta de resolución motivada. Por lo general, toda esta información quedaba recogida en los expedientes personales correspondientes, que en su momento fueron remitidos al Ministerio de Educación Nacional, pero en algunos casos las comisiones podían guardar copia de parte de esa documentación. En algunos archivos provinciales es posible encontrar rastros de la misma, así como en los lugares donde las comisiones depuradoras tuvieron su sede (por lo general, un instituto de bachillerato

14 Algunas de estas resoluciones también se publicaron (a partir de 1938) en el Boletín Oficial del Ministerio de Educación Nacional (BOMEN), pero, de manera inexplicable, el número de las que no lo fueron es superior al de las publicadas, lo que hace de esta fuente un instrumento inservible si no se complementa con otras, por lo que los estudios realizados teniéndola como única referencia pueden considerarse perfectamente prescindibles; así, GONZÁLEZ-AGÀPITO, Josep y Salomó MARQUÈS i SUREDA, La repressió del professorat a Catalunya sota el franquisme (1939-1943), segons les dades del Ministeri d'Educació Nacional, Barcelona 1996.

15 Así, por orden de publicación, URÍA, Jorge: «La depuración de maestros asturianos en los años 40": Andecha pedagógica 12 (1984) 9-11, y del mismo autor, Cultura oficial e ideología en la Asturias franquista: el I.D.E.A., Oviedo 1984, págs. 38-41; MARQUÈs, Salomó: «El magisteri públic gironí (1939-1941). La repressió»: VV.AA., La guerra civil a les comarques gironines (1936-1939), Girona 1986, págs. 395-409, y del mismo autor, «La repressió en el magisteri gironí (1939-1949)»: Butlletí de la Societat Catalana de Pedagogia 1 (1988) 17-48; Álvarez OblanCA, Wenceslao: La repressió de postguerra en León. Depuración de la enseñanza (1936-1943), León 1986; GoNZÁLEZAGÀPITO, Josep: «La repressió a la postguerra: el magisteri de les comarques de Barcelona i el professorat de batxillerat de Catalunya (1939-1949)»: Butlletí de la Societat Catalana de Pedagogia 1 (1988) 6-16; HeRNÁNDEZ HERNÁNDEZ, José M.: «La represión franquista sobre los maestros en la provincia de Santa Cruz de Tenerife»: Revista Periferia (Aula de Cultura de Geografia e Historia de la Universidad de La Laguna) 4 (1989) 93-105; y NASARRE LÓPEZ, José María: «Depuración de maestros en la provincia de Huesca»: La Universidad española bajo el régimen de Franco (Actas del Congreso celebrado en Zaragoza entre el 8 y el 11 de noviembre de 1989), Zaragoza 1991, págs. 213-235. 
de la localidad). Ni que decir tiene que se trata de una información de gran riqueza y que permite entrar de lleno en los entresijos de la depuración ${ }^{16}$.

16 La obra citada sobre la depuración en Burgos está construida precisamente sobre parte de la documentación generada por la comisión depuradora provincial («actas, listas, ficheros, informes sobre maestros, denuncias y, sobre todo, dictámenes»), que fue encontrada en el archivo del Instituto de Bachillerato «Cardenal López de Mendoza» de Burgos [CRESPO ReDONDO, Jesús et al.,: op. cit., pág. 71; la combinación de esta documentación y de las publicaciones oficiales (BOE y $B O P$ de $B$ urgos) permitió a los autores hacer un completo y exhaustivo análisis de la depuración en esa provincia, tanto desde el punto de vista cuantitativo como de los aspectos cualitativos. Igualmente, mi estudio sobre la depuración en la provincia de Barcelona se basa en las publicaciones oficiales y en el Libro de Actas de la comisión depuradora del Magisterio de Barcelona, depositado en el archivo del Instituto de Enseñanza Secundaria «Ausiàs March» de Barcelona, y que contiene abundante y rica información sobre todos los expedientes en los que la comisión encontró material susceptible de dar lugar a algún tipo de acusación contra los maestros interesados [MORENTE VALERO, Francisco: Tradición y represión..., op.cit.]. También se vale de materiales generados por la comisión depuradora (y depositados en el Archivo Histórico Provincial de Albacete) Manuel OrTIZ Heras, «La depuración del magisterio en la provincia de Albacete. El lenguaje de los expedientes de depuración»: La Universidad española..., op. cit., págs. 237-255, si bien se trata de una aportación de menor envergadura que las anteriores y muy poco sistemática por lo que hace a los aspectos cuantitativos (que, todo hay que decirlo, no son el objeto central del trabajo). También hay restos documentales de la actuación de la comisión depuradora de Huesca en su Archivo Histórico Provincial; J.M. Nasarre la ha utilizado para la confección del trabajo citado en la nota anterior. Sobre la documentación de la comisión provincial de Murcia (incluido su libro de actas) se basa en gran medida el trabajo de Ramón JIMÉNEZ MADRID, La depuración de maestros en Murcia $1939-1942$ (primeros papeles), Murcia 1997 (la documentación se encontró en el archivo del Instituto Alfonso X el Sabio, de la capital de provincia). Un caso especial es el de la depuración en Navarra; en esta provincia, la labor depuradora corrió a cargo de la Junta Superior de Educación de Navarra, con cuyos fondos documentales ha trabajado Reyes Berruezo, aportando valiosa, aunque escueta, información al respecto en su obra sobre la eduación en Navarra durante la Segunda República y la guerra civil [BERRUEZO ALBÉNIZ, Reyes, Política educativa en Navarra 1931-1939, Pamplona 1991, págs. 147-156]. En los archivos provinciales puede encontrarse otra documentación diversa a partir de la cual reconstruir, aunque con lagunas (y con mucha cautela) la depuración; es lo que ha hecho Xosé Manuel Cid Fernández para la provincia de Orense, valiéndose de nóminas, relaciones de sancionados, listas de afiliados a la Asociación de Trabajadores de la Enseñanza, etc.; no obstante, el no haber recurrido a las publicaciones oficiales para contrastar esos datos hace que las cifras que se aportan deban ser consideradas, y el propio autor así lo reconoce, como meramente provisionales: CID FERNÁNDEZ, Xosé Manuel, Educación e Ideoloxía en Ourense na II ${ }^{a}$ República (Organización e acción socioeducativa do Maxisterio Primario), Santiago de Compostela 1989. Para acabar, hay que citar el libro de Santiago MiRó, Maestros depurados en Baleares durante la Guerra Civil, Palma de Mallorca 1998, que se sirve también del libro de actas de la comisión depuradora correspondiente; no obstante, se trata de una obra peculiar en el conjunto de los estudios que se ocupan de la depuración del Magisterio, pues opta por ofrecer un cuadro impresionista, e interesante, de dicha depuración, pero sin entrar en la sistematización de los datos y rehuyendo cualquier análisis cuantitativo de los mismos. Algo parecido cabe decir del análisis disponible sobre la depuración en Las Palmas; sus autores manejan fondos de Gobernación depositados en el Archivo Histórico Provincial, lo que les permite una aproximación cualitativa al fenómeno represivo en el conjunto de la enseñanza en esa provincia canaria, pero sin poder aportar cifras al respecto: véase ANAYA HernándeZ, Luis Alberto, AlCARAZ AbelláN, José, Millares CANTERo, Sergio, Orihuela SuÁreZ, Alexis y SuÁrez Bosa, Miguel: «La represión franquista en la

Hispania, LXI/2, núm. 208 (2001) 661-688 
En cualquier caso, la fuente de información por excelencia para el estudio de la depuración del Magisterio son los mismos expedientes confeccionados por las distintas comisiones depuradoras y que, a medida que iban siendo completados, se remitían al Ministerio de Educación Nacional para su resolución definitiva ${ }^{17}$. El estudio de los expedientes de depuración se hace indispensable para cualquier trabajo que pretenda ir más allá del mero recuento de sanciones; en ellos se puede encontrar no sólo la mecánica exacta de todo el proceso, sino también aquellos aspectos que vengo denominado cualitativos y que son los que hacen comprensible el sentido exacto de la purga: desde los fundamentos ideológicos de la misma, hasta la forma en que los propios interesados afrontaron su situación, pasando por el complejo mundo de colaboración y complicidad que fue necesario para que la depuración pudiera llevarse a cabo ${ }^{18}$.

La aproximación más compleja al fenómeno depurador será, pues, la que surja del uso combinado de las fuentes anteriormente citadas, sin descartar otras posibles, entre las que los testimonios orales pueden adquirir una relevancia especial ${ }^{19}$. Ahora bien, se ha de señalar que ni siquiera la explotación sistemática y exhaustiva de todas las fuentes existentes y disponibles en estos mo-

enseñanza en la provincia de Las Palmas, 1936-1939»: Revista Guiniguarda (Universidad de La Laguna) 3 (1987) 203-221.

17 Estos expedientes se encuentran depositados en el Archivo General de la Administración (AGA), con sede en Alcalá de Henares. En total, hay 52.074 expedientes de depuración, ordenados mediante lejajos clasificados por provincias (aunque en algunos de ellos hay expedientes correspondientes a dos o más provincias); cada expediente se identifica mediante dos números: el primero indica el legajo, y el segundo el número de orden que ocupa aquél.

18 Son pocos los trabajos que, hasta este momento, han hecho uso de los expedientes de depuración de maestros; la primera utilización sistemática de estos fondos del AGA tuvo lugar durante mi investigación sobre la depuración en la provincia de Barcelona, y que se tradujo en una memoria de Tercer Ciclo presentada en la Universidad Autónoma de Barcelona en 1990; puede verse un amplio extracto de ese trabajo en MORENTE VALERO, Francisco: Tradición y represión..., op. cit.; posteriormente, los expedientes de depuración se han convertido en parte fundamental de un estudio sobre la depuración de maestros vascos [OSTOLAZA ESNAL, Maitane, op. cit.], así como de mi trabajo sobre la depuración en trece provincias españolas, que pretende una primera aproximación a lo que pudo ser el conjunto del proceso depurador [MORENTE VALERO, Francisco: La escuela y el Estado Nuevo..., op. cit.], y del ya citado sobre la depuración en Valencia [del que sus autores dieron una primera noticia en FERNÁNDEZ SORIA, Juan Manuel y $\mathrm{M}^{\mathrm{a}}$ del Carmen Agulló DíAZ: «La depuración franquista del magisterio primario»: Historia de la Educación 16 (1997) 315-350].

19 Los diferentes archivos provinciales, así como los de diversas instituciones, por otra parte, pueden deparar información complementaria de inestimable importancia; así, por ejemplo, el estudio sobre la depuración en Barcelona se benefició de un completo archivo con las fichas personales de los maestros y maestras que ejercieron en la provincia en los primeros años cuarenta, y que incorporaban datos sobre los servicios prestados y sobre la propia depuración; tal fichero se encontraba depositado en una dependencia del Departament d'Ensenyament de la Generalitat de Catalunya (heredera de los fondos de la antigua Delegación Provincial del Ministerio de Educación); los archivos de las universidades también pueden aportar datos de interés sobre la depuración y, en especial, sobre algunos miembros de las comisiones depuradoras. 
mentos permitiría llegar a lo que podríamos llamar, parafraseando una conocida obra de Salas Larrazábal, los datos exactos de la depuración franquista del Magisterio. Y ello porque todas y cada una de las fuentes muestran serias limitaciones para ese fin; ya me he referido al hecho de que, de forma inexplicable, no todas las resoluciones definitivas de expedientes de depuración eran publicadas, como resultaba preceptivo, en los Boletines Oficiales correspondientes; por otra parte, los más de cincuenta y dos mil expedientes de depuración depositados en el AGA distan de ser la totalidad de los tramitados, sin que tampoco sea posible explicar de forma convincente el porqué de algunas amplias lagunas en la documentación ${ }^{20}$. Así pues, es factible llegar a tener un conocimiento bastante exacto de las cifras de depurados en algunas provincias, pero será del todo imposible hacerlo en otras; de ello se deriva que los datos globales de la depuración de maestros en España nunca se podrán establecer con total exactitud, si bien la aproximación final adolecerá sólo de un pequeño margen de error, irrelevante en cualquier caso a efectos de extraer conclusiones más que definitivas sobre todo el proceso.

\section{Las víctimas de la depuración}

Las primeras disposiciones oficiales en materia de depuración que publicaron los militares sublevados hacían referencia expresa a que sólo los maestros titulares serían objeto de la misma; no obstante, la posterior regulación del proceso depurador fue ampliando considerablemente los grupos de afectados ${ }^{21}$, e incluso las comisiones depuradoras, por su cuenta y riesgo, llegaron a tramitar expedientes de maestros que, en principio, no entraban dentro de alguno de

\footnotetext{
20 Así, por ejemplo, sólo hay en el AGA 197 expedientes de la provincia de Zaragoza, cuando los depurados debieron de superar ampliamente el millar (en 1931 eran 1.063 los maestros que ejercían en la provincia, y su número hasta 1936 sin duda se incrementó; cfr. PÉREZ GALÁN, Mariano: La enseñanza en la Segunda República, Madrid 1988, pág. 288. Más llamativa es la situación de Navarra: 67 expedientes depositados en el AGA, cuando en julio de 1936 eran 1.101 los maestros destinados en esa provincia; cfr. BERRUEZO AlBÉNIZ, Reyes: op. cit., pág. 148. La situación por provincias es muy desigual, aunque en bastantes de ellas el número de expedientes disponibles debe aproximarse mucho a la totalidad de los tramitados; es el caso, por ejemplo, de Barcelona, Girona, Granada, Madrid o Valencia, por citar algunas de las provincias que he podido trabajar y en las que el número de expedientes disponibles en el AGA supera al de maestros que ejercían en ellas en 1935 (según los últimos datos del Ministerio de Instrucción Pública, recogidos en MOLERO PINTADO, Antonio: La reforma educativa de la Segunda República Española. Primer Bieno, Madrid 1977, pág. 418) en una cifra que podría razonablemente corresponder al incremento de plantilla del curso 19351936, más los maestros interinos, sustitutos e incluso privados que fueron depurados, así como los alumnos de las Escuelas Normales que igualmente fueron objeto de depuración y cuyos expedientes están junto con los de los maestros.

21 Para un detenido análisis de la legislación depuradora, véase MORENTE VALERO, Francisco: La escuela y el Estado Nuevo..., op. cit., págs. 187-219.
} 
los colectivos directamente señalados en la normativa depuradora ${ }^{22}$. En cualquier caso, para continuar en el ejercicio de la docencia, tuvieron que solicitar su depuración (pues los expedientes no se tramitaban de oficio) todos los maestros funcionarios, los interinos, los sustitutos, así como los que trabajaban en las fundaciones benéfico-docentes. Los maestros de escuelas privadas fueron depurados por las propias empresas, si bien bajo la atenta vigilancia de las comisiones depuradoras que, entre otras cosas, debían velar por que ningún docente público inhabilitado temporal o definitivamente encontrase refugio en la enseñanza privada ${ }^{23}$. Finalmente, la depuración afectó también al alumnado de las Escuelas Normales, en una decisión que era plenamente congruente con el carácter preventivo (además de, obviamente, punitivo) que tenía todo el proceso, y que José María Pemán, presidente de la Comisión de Cultura y Enseñanza de la Junta Técnica del Estado, se encargó de recordar en una de sus más célebres Circulares ${ }^{24}$.

De esta manera, no hay ninguna duda a la hora de establecer quién fue objeto de la depuración del Magisterio; otra cosa, como ya se ha dicho, es saber el número de quienes fueron objeto de la misma. Se puede hacer, sin embargo, una primera aproximación a partir de las fuentes disponibles. Según la última estadística oficial del Ministerio de Instrucción Pública, el número de maestros y maestras nacionales en el escalafón de 1935 era de $50.527^{25}$. A esta cifra se le deberían añadir los incorporados al escalafón antes de julio de 1936, así como los docentes interinos y sustitutos que ejercieron durante el curso 1935-1936 (o en años anteriores) ${ }^{26}$ - cifras ambas imposible de establecer con exactitud; igualmente, se debería añadir la totalidad del alumnado que estaba cursando

22 Así, por ejemplo, maestros que ejercían la profesión de manera privada, o religiosos -incluso sin el título de Magisterio- que enseñaban en escuelas de las distintas órdenes religiosas. En el primer caso, la solicitud de depuración era imprescindible para poder seguir ejerciendo privadamente la profesión; en el segundo caso el trámite era tan irrelevante que bastaba un aval del superior jerárquico del religioso solicitante para que la comisión, sin más consideraciones, procediese a resolver favorablemente el expediente.

23 Orden del Ministerio de Educación Nacional de 14 de mayo de 1938.

24 Circular de 7 de diciembre de 1936 (BOE del 10). La circular, dirigida a los vocales de las comisiones depuradoras, era de una dureza inaudita; en realidad, su redacción fue obra de Eugenio Vegas Latapie, miembro de la Comisión de Cultura y Enseñanza, y Pemán la firmó, aparentemente, sin haberla leído. A posteriori, Pemán se quejó ante Vegas de que el contenido de la Circular le había hecho aparecer ante la opinión pública como -en sus propias palabras- «el Torquemada de esta Inquisición», con el consiguiente irreparable daño para su imagen, todo lo cual no dejó de provocar la consecuente indignación de Eugenio Vegas; cfr. VEGAS LATAPIE, Eugenio: Los caminos del desengaño. Memorias políticas (II) 1936-1938, Madrid 1987, págs. 104 y ss.

25 Molero PinTado, Antonio: op. cit., pág. 418.

26 Hay que recordar que la depuración se realizó sobre el personal que ejercía antes del 18 de julio de 1936; todos los incorporados a la enseñanza en la zona republicana durante la guerra fueron directamente considerados sin ningún tipo de derechos, y, en caso de pretender volver a enseñar, tuvieron que aportar los avales y garantías político-ideológicas que se exigieron al nuevo profesorado interino o a quienes se presentaron a las oposiciones que, en su momento, se convocaron. 
estudios de Magisterio en el momento de estallar la guerra civil. En el caso de Barcelona, todos estos contingentes supusieron alrededor de un $20 \%$ sobre la plantilla de 1935; si el porcentaje fuese similar en el conjunto de las provincias españolas, se podría considerar que una cifra de 61.000 expedientes de depuración tramitados no se situaría muy lejos de lo que debió de ser el montante de la depuración en el conjunto de España ${ }^{27}$.

Aún hay otra cuestión, por lo que hace a los sujetos de la depuración, que las fuentes no permiten aclarar con facilidad, y es la categoría en que cada uno de los expedientados debe ser situado. Sin duda, los expedientes ofrecen al respecto la mejor información, pero no siempre es correcta (o está suficientemente actualizada); así, no es infrecuente que la categoría (propietario, interino, sustituto, alumno...) que figura en el expediente y la que aparece en el Boletín Oficial no coincida. Por otra parte, en muchas provincias las relaciones de resoluciones de expedientes de depuración que se publicaban en el Boletín sólo indicaban el nombre del interesado y la resolución recaída en su expediente, sin mayores indicaciones de categoría o localidad en la que hubiese ejercido. Todo ello hace que, a la hora de ofrecer cifras de sanciones, no sea posible muchas veces diferenciar entre las diversas categorías, ni siquiera por lo que respecta a los alumnos normalistas ${ }^{28}$.

\section{La mecánica depuradora}

A partir de la legislación aplicada, así como del estudio detallado de los expedientes de depuración, puede establecerse la mecánica que seguía la tramitación completa de un expediente de depuración. En síntesis, era la siguiente: la persona interesada en continuar ejerciendo la docencia (o de reincorporarse a ella) debía solicitarlo mediante una instancia que debía ir acompañada de una declaración jurada sobre sus actividades políticas y sindicales antes y durante la guerra, así como de su actuación concreta ante el Movimiento Nacional. Con ambos documentos, la comisión depuradora abría el expediente de depuración; a continuación, la comisión recababa los informes sobre el interesado que la legislación consideraba preceptivos (y que eran los del alcalde, el párroco, la Guardia Civil y un padre de reputación intachable de la localidad, o localidades, donde el maestro hubiese ejercido en los últimos años). La comisión podía solicitar otros informes de otras instancias, así como tener en cuenta todo tipo de denuncias (públicas o anónimas) que pudiesen existir contra la persona obje-

\footnotetext{
27 De donde se sigue que en el AGA faltarían en torno a nueve mil expedientes.

28 En cualquier caso, ello no distorsiona los resultados de la depuración. El contabilizar conjuntamente a maestros y alumnos de las Normales es la consecuencia lógica del carácter global de todo el proceso, así como de la ya citada intención preventiva del mismo; al fin y al cabo, los alumnos de hoy iban a ser los maestros de mañana, $y$, de hecho, bastantes ya habían acabado los estudios en el momento de completarse su expediente.
}

Hispania, LXI/2, núm. 208 (2001) 661-688 
to de expediente, incluyendo las que sus compañeros hubiesen podido hacer en sus respectivas declaraciones juradas (en las que eran interrogados precisamente sobre esa cuestión). Con toda esta información, la comisión procedía a valorar si había algún elemento merecedor de sanción; en caso negativo, se daba por cerrado el expediente con una propuesta de confirmación en el cargo o en los derechos a que hubiere lugar. En caso positivo, la comisión formulaba por escrito un pliego de cargos que el interesado debía contestar en el plazo improrrogable de diez días desde su recepción. Para rebatir los cargos no bastaba con su simple refutación por escrito, sino que las comisiones conminaban a la presentación de pruebas documentales (incluyendo avales de personas solventes) que, de forma concluyente, deshicieran los indicios de culpabilidad. Una vez recibido el escrito de defensa, con la documentación complementaria que el interesado hubiese podido aportar, la comisión procedía a su valoración y a la resolución del expediente (si bien, en ocasiones, podía decidirse una ampliación de información, reiniciándose así el trámite), lo que se hacía mediante votación y por mayoría (la legislación contemplaba la posibilidad de recoger votos particulares, aunque, como muestra el estudio de los expedientes, tal hecho se dio en muy contados casos).

Una vez cerrado el expediente con una propuesta de resolución (absolutoria o sancionadora), se enviaba a la Comisión de Cultura y Enseñanza (desde febrero de 1938, al Ministerio de Educación Nacional), donde era examinado de nuevo y donde se establecía la resolución definitiva, que podía coincidir o no con la propuesta de la comisión ${ }^{29}$; en algunas ocasiones, incluso, se devolvía el expediente a la comisión provincial con indicación de que se procediese a nuevas actuaciones y a un nuevo examen del mismo. Como se verá más adelante, no fue infrecuente que las instancias ministeriales modificasen la propuesta de resolución de las comisiones, hasta el punto de que, en algunos aspectos, puede hablarse de una rectificación en toda regla del trabajo de éstas.

\footnotetext{
29 Los expedientes que se tramitaron y resolvieron durante 1936 y 1937 fueron reexaminados personalmente por los tres miembros de la Comisión de Cultura y Enseñanza de la Junta Técnica del Estado responsables de la Enseñanza Primaria, a saber, su vicepresidente, Enrique Suñer, y los vocales Eugenio Vegas y Mariano Puigdollers, cuyas firmas figuran al pie de la resolución definitiva de cada expediente. Con la creación del Ministerio de Educación Nacional, y dado el volumen que iba alcanzando la depuración, el examen de cada expediente por parte del Ministro (Pedro Sainz Rodríguez) o del Jefe Nacional del Servicio de Enseñanza Primaria (Romualdo de Toledo) devino imposible; por ello, por la Orden de 11 de marzo de 1938, se creó una Oficina Técnico-Administrativa, encargada entre otras cosas de reexaminar los expedientes que llegaban desde las comisiones provinciales y de formular una propuesta razonada de resolución de los mismos, que era la que se elevaba a las altas instancias del Ministerio. Esa función fue asumida a partir de marzo de 1939 por la Comisión Superior Dictaminadora de expedientes de depuración, creada por la Orden de 18 de marzo de 1939 que vino a refundir toda la normativa depuradora anterior y que fue la que se aplicó en el territorio que se mantuvo republicano hasta el final de la guerra (así como en los expedientes que aún seguían tramitándose en otras provincias anteriormente liberadas).
}

Hispania, LXI/2, núm. 208 (2001) 661-688 
Por otra parte, cabe preguntarse en qué medida la depuración fue un proceso uniforme en el conjunto de España, o dicho de otra manera, si pueden apreciarse diferencias significativas entre lo actuado en las diferentes provincias. Por lo que hace a los resultados de la depuración discutiremos la cuestión en otro apartado; en lo que se refiere al procedimiento, hay que decir que, con la ya citada excepción de Navarra, la depuración fue acometida por el mismo tipo de comisiones y siguiendo exactamente la misma legislación, independientemente del momento en que el proceso se puso en marcha. Los maestros que habían sido depurados de forma inmediata al inicio de la guerra vieron cómo sus expedientes se rehacían siguiendo las pautas de la normativa que estableció las comisiones y sus criterios de actuación. Así pues, el contenido de los expedientes y el conjunto de los trámites con ellos seguidos fueron básicamente iguales en todas las provincias.

No es ésta, sin embargo, una opinión unánime. M. Ostolaza ha defendido que, para el País Vasco, puede hablarse de un modelo propio de depuración. Por lo que hace al procedimiento depurador (lo referente a sus efectos se discutirá más adelante), Ostoloza funda su opinión en la existencia de una legislación depuradora especial para Guipúzcoa y Vizcaya que quedó reflejada en una circular del Rectorado de Valladolid dirigida a las comisiones depuradoras de ambas provincias (30 de abril de 1937) en la que se explicaba que era en Vizcaya donde más se habían hecho sentir los efectos del nacionalismo vasco, por lo que, en las palabras de la propia circular, «el procedimiento de depuración y rehabilitación del personal de los Establecimientos docentes tiene que ostentar caracteres distintos de los aplicados en otras provincias liberadas de la esclavitud marxista», por lo que se establecía la «suspensión provisional de empleo y sueldo de todos los funcionarios de la Enseñanza en Vizcaya, sean del Estado, Provincia o Municipio y pertenezcan al Escalafón técnico, administrativo o subalterno», pudiendo reingresar sólo quienes acreditasen suficientemente «su excelente condición pretérita y actual, en los órdenes religioso, moral y social» ${ }^{30}$. Para la autora, la excepcionalidad de esta disposición descansa en que delimitaba territorialmente su campo de acción, afectaba a la totalidad de maestros independientemente de su condición y situación, y, «a diferencia de lo que ocurría con las leyes depuradoras generales, prevalecía la presunción de culpabilidad» ${ }^{31}$.

Lamento discrepar de la opinión de la autora de, por lo demás, tan excelente estudio sobre la depuración en Guipúzcoa. En primer lugar, estamos ante una circular de un Rectorado, disposición de rango legal inferior a una Orden Ministerial como la que reguló la depuración en la provincia de Vizcaya ${ }^{32}$. En

30 OstolaZA ESNAL, Maitane: op. cit., pág. 120.

31 Ibidem.

32 Orden de 3 de julio de 1937 (BOE del 4). Nótese que la orden es posterior a la circular, por lo que ni siquiera cabe argumentar que ésta interpretaba lo establecido en aquélla.

Hispania, LXI/2, núm. 208 (2001) 661-688 
segundo lugar, la publicación de disposiciones legales que acotaban la depuración en un territorio determinado fue algo absolutamente habitual: se hacía siempre que se liberaba algún nuevo territorio; así se hizo, por ejemplo, además de con Vizcaya, con Santander, Asturias, Aragón y Cataluña ${ }^{33}$; ninguna de estas disposiciones incluía nada que no estuviese recogido en la normativa depuradora general, y se publicaban como mero recordatorio de la misma. Item mas, que la depuración en Vizcaya afectase a todos los maestros (y trabajadores de la educación administrativa) independientemente de su situación y condición profesional era exactamente lo mismo que ocurría en todas las demás provincias (recuérdese que la normativa general establecía que nadie podía ejercer la docencia, ni en establecimientos públicos, ni en centros privados, ni particularmente, sin haber pasado previamente el trámite depurador). Finalmente, en todas partes (y no sólo en Vizcaya) se decretaba la suspensión provisional y la exigencia de solicitar el reingreso para todos los docentes, mientras que la presunción de culpabilidad fue algo que funcionó de manera universal, como el análisis de los expedientes tramitados por distintas comisiones depuradoras, así como de la documentación ministerial, demuestra suficientemente ${ }^{34}$.

En definitiva, por lo que hace al procedimiento, creo que se puede concluir que la depuración del Magisterio se caracterizó por una notable uniformidad en el conjunto del Estado. Ello no fue óbice, sin embargo, para que se diesen algunas particularidades que merecen ser comentadas. Por un lado, es evidente que la propia composición de las comisiones depuradoras debió de influir en la aplicación de los criterios establecidos en la normativa, si bien no parece que pueda hablarse de grandes diferencias ideológicas entre los miembros de unas y otras comisiones, y, por tanto, entre el trabajo realizado por cada una de ellas. Otro elemento a considerar es el relativo a los documentos incorporados a los expedientes; así, mientras la declaración jurada que tenían que presentar los maestros se atuvo a un modelo oficial de interrogatorio ${ }^{35}$, los informes preceptivos que debían recabarse se obtuvieron a partir de formularios muy diversos. Dichos formularios eran elaborados por las propias comisiones depuradoras, lo que dio lugar a una enorme variedad de modelos: desde la simple petición de información sobre la conducta política, social, religiosa y moral del maestro, sin

33 Orden de 1 de septiembre de 1937 ( $B O E$ del 3), para Santander; Orden de 19 de noviembre de 1937 ( $B O E$ del 13), para Asturias; Orden de 8 de abril de 1938 (BOE del 11) para las provincias aragonesas; y Orden de 28 de enero de 1939 (BOE del 3 de febrero), para Cataluña.

34 Véase Morente VAlero, Francisco: La escuela y el Estado Nuevo... , op. cit., especialmente los capítulos IV y V de la segunda parte, págs. 257-398.

35 Hubo muy pocas excepciones al respecto; la diferencia más significativa fue que, en algunas provincias, el impreso de la declaración jurada no incorporaba un último apartado en el que se interrogaba al interesado sobre la conducta de sus compañeros. Hay que hacer notar, por otra parte, que no siempre los impresos eran iguales, o que el orden en que se formulaban las preguntas no era idéntico, pero, en esencia, tanto el tenor como el contenido del interrogatorio venían a ser plenamente coincidentes. 
incorporación de cuestionario alguno (lo que permitía a los informantes contestar de forma libre y no dirigida), hasta impresos con un interrogatorio en extremo detallado y minucioso, pasando por situaciones intermedias en las que sin indagar de forma exhaustiva, sí se incluían cuestiones concretas sobre las que se debía contestar ${ }^{36}$. No obstante, y a pesar de estas diferencias tipológicas, el contenido de los informes oficiales acababa teniendo unas características muy similares en todas partes; por lo general eran escuetos y carentes de matices (especialmente en las localidades de más población), escasamente rigurosos, llenos de imprecisiones (cuando no estaban directamente basados en rumores), etc.; las contradicciones entre unos y otros eran constantes (o, al contrario, las coincidencias eran tan asombrosas que fácilmente se descubría una única fuente de inspiración para todos ellos ${ }^{37}$ ). Por supuesto, se dio también la situación contraria, es decir, informes completos, detallados, pormenorizados y redactados con fundamento de causa; sin embargo, esto último no fue lo más habitual, por lo que puede afirmarse sin temor a equivocación que el conjunto de la depuración se edificó sobre bases documentales que en cualquier procedimiento jurídico mínimamente exigente hubiese conducido sin remedio a la declaración de absoluta nulidad de todo lo actuado ${ }^{38}$.

A pesar de esta uniformidad en los procedimientos seguidos y en el contenido de los expedientes de depuración, es cierto que los criterios de actuación de las comisiones depuradoras no eran siempre coincidentes. Así, por ejemplo, había comisiones que formulaban acusaciones por hechos a los que otras no daban la menor importancia ${ }^{39}$, o que sancionaban de forma diferente a como lo hacían otras conductas que eran perfectamente análogas. La misma forma de instruir el expediente de depuración ya podía condicionar el resultado final del mismo, y la valoración que se hacía tanto de los informes recibidos como de las

36 En el primer grupo se incluían los impresos de las comisiones de Almería, Baleares, Córdoba, Guipúzcoa, Huelva, Jaén, León, Málaga, Murcia y Palencia. Los interrogatorios más exhaustivos eran los de las comisiones de Álava, Burgos, Castellón, La Coruña, Girona, Guadalajara, Logroño, Lugo, Madrid, Las Palmas, Santander, Tarragona, Toledo y Valladolid. Un caso curioso es el de la comisión de Tenerife, que enviaba cuestionarios diferentes a los distintos informantes: así, a la Guardia Civil y a los alcaldes se les interrogaba sobre cuestiones políticas y sociales; al párroco sobre cuestiones religiosas y morales, y al padre de familia sobre los aspectos docentes.

37 En ocasiones tal hecho ni se intentaba ocultar: informes procedentes de fuentes teóricamente distintas, pero absolutamente coincidentes y escritos por la misma mano, o, en el colmo de la desidia y la desfachatez, calcados mediante papel carbón; ejemplos de ello en AGA, expedientes de depuración de maestros, expedientes número 166-13, 230-11 y 64-21; también en Archivo Central del Ministerio de Educación, Resoluciones de expedientes de revisión, caja 83.714, resolución 3.275.

38 Para un detallado análisis de todas las cuestiones precedentes, véase MORENTE VALERO, Francisco: La escuela y el Estado Nuevo..., op. cit., págs. 257-271.

39 La de Asturias, por ejemplo, acusaba de colaboración con las autoridades republicanas a todos los maestros que no habían sido destituidos por éstas durante la guerra, dando por sentado que ello era prueba de, como mínimo, adaptación a las circunstancias, cuando no de identificación con las mismas.

Hispania, LXI/2, núm. 208 (2001) 661-688 
pruebas de defensa aportadas por los maestros no siempre era equiparable entre unas comisiones y otras. De todo ello debería seguirse que la depuración careció de homogeneidad en el conjunto de las provincias, pero sería ésta una conclusión precipitada. No se ha de olvidar que los expedientes elaborados por las comisiones eran enviados a las autoridades educativas centrales, que procedían a un nuevo estudio del mismo; y no se crea que esta fase era un puro trámite, pues como los propios expedientes permiten comprobar, el examen que se hacía de los mismos era minucioso, y su rastro se ha conservado en la forma de escritos que no pocas veces eran enormemente duros en las consideraciones que se hacían sobre el trabajo desarrollado por la comisión correspondiente. El hecho de que todos y cada uno de los expedientes tramitados fuesen reexaminados por una única comisión (como se recordará, la Oficina TécnicoAdministrativa, y más tarde la Comisión Superior Dictaminadora) hace que, pese a las posibles variaciones provinciales que puediesen detectarse en el trámite de los expedientes, su resolución final estuviera regida por criterios más o menos homogéneos en la valoración de las pruebas y en las sanciones aplicadas a los diferentes tipos de conductas objeto de escrutinio.

\section{El resultado de la depuración}

El análisis cuantitativo de la depuración, como ya se comentó anteriormente, presenta una primera dificultad: el número limitado de estudios provinciales existentes que ofrezcan mínimas garantías de exhaustividad. Además, algunos de los estudios disponibles, como el de Álvarez Oblanca sobre León, o el de Cid Fernández sobre Orense, no sirven a tal efecto pues los maestros contabilizados en el primero de ellos quedan muy lejos del número total de depurados en esa provincia ${ }^{40}$, mientras que los datos del segundo, por las fuentes utilizadas para obtenerlos, el propio autor reconoce que sólo pueden considerarse como orientativos $^{41}$. El estudio de J.M. Hernández sobre Santa Cruz de Tenerife, por su parte, es un ejemplo interesante de la depuración que se llevó a cabo en los primeros meses de la guerra civil, antes de que se constituyesen las

40 Álvarez Oblanca recoge en los anexos de su libro un total de 889 resoluciones de expedientes, cuando los maestros que ejercían en la provincia en 1935 eran, según sus propios datos, 1.964; cfr. Álvarez OBlanCA, Wenceslao: op. cit., págs. 19 y 123-152.

41 Cid FernándeZ, Xosé Manuel: op. cit., p. 89. Más recientemente, Antón Costa Rico, en «A chegada da dictadura. Purga e represión de ensinantes (1936-1940)»: Revista Galega de Educación 28 (1.997) 88-91, ha ofrecido datos de la depuración en las cuatro provincias gallegas, pero se trata de cifras parciales (correspondientes sólo a los años 1936 y 1937), y sin que se indique las fuentes a partir de las cuales se han confeccionado (aunque parece deducirse que se trata una vez más de los BOP correspondientes); por otra parte, sólo se recogen dos modalidades de sanción (separación del servicio y suspensión temporal de empleo y sueldo con traslado a otra escuela) todo lo cual hace que los datos relativos al magisterio gallego en su conjunto continúen pendientes de elaboración.

Hispania, LXI/2, núm. 208 (2001) 661-688 
comisiones depuradoras según los criterios establecidos por la Junta Técnica del Estado (JTE), pero elude cualquier referencia a la actuación de la comisión tinerfeña consituida a partir de las disposiciones legales emanadas de la Comisión de Cultura y Enseñanza de la JTE ${ }^{42}$. El trabajo de Nasarre López sobre Huesca, a su vez, no sistematiza los datos recabados del BOP (que, por otra parte, se quedan algo lejos de la totalidad de maestros depurados en la provincia) por lo que hace difícil su utilización para un cómputo global de la depuración, y prácticamente la misma consideración se puede hacer sobre el estudio de J. Uría sobre Asturias ${ }^{43}$. Algo similar ocurre con la aportación de Salomó Marquès sobre Girona: el autor contabiliza un total de 786 resoluciones de expedientes, cuando los depositados en el AGA correspondientes a esa provincia suman 1.022 ${ }^{44}$. Finalmente, como ya se dijo, en los estudios de Miró sobre Baleares, y de Anaya, Alcaraz, Millares, Orihuela y Suárez sobre Las Palmas, se renuncia a cualquier concreción cuantitativa.

No obstante todo lo anterior, disponemos de suficientes estudios provinciales fiables como para abordar una aproximación a los datos globales de la depuración, aceptando siempre, eso sí, un cierto margen de error en la estimación.

42 En efecto, en septiembre de 1936, el Comandante Militar de la Provincia de Santa Cruz de Tenerife ordenó la creación de una comisión depuradora del Magisterio que funcionó hasta la creación de las comisiones depuradoras por parte de la JTE. En apenas tres meses, dicha comisión expedientó a todo los docentes tinerfeños y resolvió sus expedientes; el resultado de dicha depuración se concretó en cuatro resoluciones publicadas en el BOP de Tenerife los días 18 de septiembre, 23 de septiembre, 9 de noviembre y 9 de diciembre de 1936; véase HernÁNDEZ HeRnÁNDEZ, José M.: op. cit., p. 99 y p. 105 , nota 28 . Todo ello da idea de la celeridad del procedimiento y, consiguientemente, de la falta de garantías del mismo. En cualquier caso, la normativa depuradora establecía que debía reiniciarse el proceso desde el principio. El autor del artículo no da noticia de esa segunda operación, por lo que es difícil saber si los datos correspondientes a la primera depuración se vieron o no alterados en la segunda. El resultado de esa depuración preliminar fue el siguiente: sobre 674 expedientados, 214 resultaron sancionados (lo que representa un 31,7\%); de ellos, 35 fueron separados del servicio, 73 resultaron inhabilitados entre 2 meses y 4 años, 102 fueron suspendidos a medio sueldo entre 15 días y 10 meses, y 4 fueron suspendidos y trasladados de escuela; Ibid., p. 101.

43 Nasarre se limita a recoger las órdenes publicadas en el $B O P$ de Huesca con resoluciones de expedientes de depuración, pero algunas de ellas incorporaban decisiones (confirmatorias o sancionadoras) de carácter provisional que no queda claro cómo evolucionan después, pues el trabajo no lo aclara. A partir de las órdenes apuntadas por Nasarre (y sin contabilizar las resoluciones que expresamente se señalan como provisionales) se pueden contar unos 865 maestros y maestras objeto de depuración. En mi particular recuento de esa provincia (a partir del BOP, el BOMEN, los expedientes de depuración depositados en el AGA y los de revisión depositados en el ACME), he podido censar un total de 965 expedientados; en el AGA, por su parte, hay depositados 978 expedientes de esa provincia; cfr. NASARRE LóPEZ, José María, op. cit., págs. 232-235, y MORENTE VALERO, Francisco: La escuela y el Estado Nuevo..., op. cit., pág. 42. Por su parte, Jorge Uría se limita a dar las cifras globales de sancionados, sin especificar qué tipo de sanciones se aplicaron y sin situarlas en relación al total de expedientes tramitados; cfr. URÍA, Jorge, Cultura oficial..., op. cit., págs. 38-39.

44 Cfr. MARQuÈs i SuredA, Salomó: op. cit., pág. 408, y Morente VAlero, Francisco: La escuela y el Estado Nuevo..., op. cit., p. 42. Mi censo para esa provincia, a partir de las fuentes citadas en la nota anterior, llega a los 1.070 expedientados (Ibidem).

Hispania, LXI/2, núm. 208 (2001) 661-688 
Para empezar, hay cinco provincias que, por las fuentes manejadas para su estudio, cuentan con trabajos que aportan cifras sobre la depuración que pueden considerarse como prácticamente definitivas: se trata de Burgos, Barcelona, Guipúzcoa, Navarra y Valencia ${ }^{45}$. Por otra parte, en mi trabajo sobre otras doce provincias españolas, he podido censar lo que seguramente fue la práctica totalidad de expedientados en Girona, Tarragona y Vizcaya ${ }^{46}$, y una cifra que está por encima del $90 \%$ del total en Albacete, Granada, Madrid y Sevilla; los datos que pude obtener para Asturias fueron de un $80 \%$ del total de expedientados, y de entre un 75 y un $80 \%$ en Huesca, Lleida, Pontevedra y Valencia ${ }^{47}$. Finalmente, en su estudio sobre Murcia, Jiménez Madrid ofrece la resolución definitiva de los expedientes del $78 \%$ de los maestros que ha podido censar (y puede deducirse, sin apenas margen de error, la del $22 \%$ restante, como después aclararé). En definitiva, podemos contar con los datos prácticamente definitivos de ocho provincias, y con cifras altamente significativas de nueve más ${ }^{48}$. Nótese, además, que se trata de provincias de características muy diversas entre sí, tanto por lo que hace a sus rasgos económicos, sociales y políticos, como a la situación en que quedaron al inicio de la guerra y a su evolución durante la misma. Esta diversidad es especialmente importante a la hora de pretender extrapolar los datos que de ellas se pudieran derivar, pues permite considerar prácticamente todas las situaciones provinciales posibles, evitando así el sesgo que tendrían los resultados del análisis si, por ejemplo, sólo contásemos con provincias eminentemente rurales, o escasamente significativas desde el punto de vista político, o que hubieran caído en poder de los nacionales desde el inicio de la guerra.

A la hora de sistematizar los datos disponibles sobre el resultado de la depuración se presenta, aún, otro problema; las sanciones que se podían aplicar eran, como se señaló, diversas, y, además, podían acumularse, lo que hace que las combinaciones posibles (atendiendo al tipo de sanción y a la duración de la misma) superen el centenar. Por otra parte, no todos los autores que se han ocupado del tema han utilizado el mismo criterio clasificatorio por lo que hace a la consignación de las sanciones. Ello obliga a presentarlas agrupándolas en grandes bloques, y dejando poco espacio para el matiz (especialmente en lo que se refiere a la duración de determinadas sanciones, o a la tipología de los traslados de localidad - dentro de la provincia, fuera de la provincia, fuera de la región...-). Hechas todas las consideraciones precedentes, los resultados de la

45 Véanse, respectivamente, las obras citadas de J. Crespo Redondo (et al.), F. Morente Valero, M. Ostolaza Esnal, R. Berruezo Albéniz, y J.M. Fernández Soria y M.C. Agulló Díaz.

46 En Girona recogí 1.070 resoluciones de expedientes, cuando en el AGA hay sólo 1.022 expedientes depositados, y los maestros que ejercían en la provincia en 1935 eran 766 . Las cifras para Tarragona son, respectivamente, 1.031, 1022 y 733; y para Vizcaya, 999, 775 y 864; cfr. MORENTE VALERo, Francisco, La escuela y el Estado Nuevo..., op. cit., pág. 42.

47 Ibid., págs. 41-43.

48 No utilizaré mis datos sobre Valencia por ser más completos los de J.M. Fernández Soria y M.C. Agulló Díaz. 
depuración del Magisterio, a la luz de los estudios hasta ahora existentes, podrían sintetizarse tal y como muestra el cuadro I.

Como puede verse, el cuadro recoge información sobre el resultado de 23.516 expedientes de depuración, lo que supone algo más de un tercio de los que, con toda probabilidad, se instruyeron en el conjunto de las provincias españolas. Teniendo en cuenta, además, lo dicho anteriormente sobre el carácter diverso de las diecisiete provincias analizadas, puede concluirse que tanto por el número de expedientes censados, como por las características de las provincias de donde proceden, los datos que el cuadro aporta son altamente significativos y pueden ser extrapolados, con escaso margen de error, para valorar el resultado de la depuración en su conjunto. La función homogeneizadora que tuvo la labor de la Oficina Técnico-Administrativa del MEN (y, más tarde, de la Comisión Superior Dictamonidara) sobre la que ya se habló más arriba no hace sino confirmar la solidez de esas cifras como elemento de referencia para establecer lo que debieron de ser los datos globales del proceso depurador.

Una primera constatación es que del total de maestros y maestras expedientados, aproximadamente la cuarta parte resultó sancionado en una u otra forma. Dicho de otro modo: tres cuartas partes de los docentes superaron el proceso depurador sin ningún efecto negativo. Teniendo en cuenta el carárcter inquisitorial que tuvo la depuración, y el rigor y el celo con que se emplearon tanto las comisiones provinciales como los organismos centrales del Ministerio, ese resultado debe hacer reflexionar sobre esa idea tan comúnmente aceptada de un Magisterio entregado en cuerpo y alma a la República y a los principios democráticos, laicos y progresistas. De hecho, los estudios que se han consagrado a la política educativa en la época republicana ya mostraban la existencia de profundas divergencias en el seno del Magisterio Nacional, así como el peso que tenían los maestros formados en los viejos planes de estudios y que permanecían anclados en la metodología y los principios pedagógicos más tradicionales; a ello se han de añadir los enfrentamientos producidos entre diversos colectivos de docentes como consecuencia de determinadas medidas de tipo político que afectaban al Magisterio (resolución del espinoso problema de las oposiciones de 1928, aplicación del Plan Profesional del Magisterio de 1931, subidas salariales no generalizadas a todos los docentes, problemas en los concursos de traslados...), así como el hecho constatable de que eran las asociaciones profesionales menos politizadas las que contaban con mayor número de afiliados, mientras que los sindicatos de docentes progresistas eran claramente minoritarios. De todo lo cual cabe concluir que la imagen del Magisterio que los publicistas de la derecha habían transmitido tenía poco que ver con la realidad: es cierto que había sectores que apoyaban abiertamente las reformas republicanas, pero sin duda había también damnificados de las mismas, así como colectivos que, por formación y adscripción ideológica, eran abiertamente contrarios a ellas; y todo ello sin contar con un contingente seguramente nada despreciable de docentes que, sencillamente, se mantuvieron al margen de los avatares polí- 
ticos y sociales de la época, limitándose al ejercicio de su profesión sin plantearse ninguna otra consideración ${ }^{49}$.

Si el porcentaje total de sancionados, aun siendo alto, quizá se queda por debajo de lo que tradicionalmente se había especulado, no se puede, sin embargo, dejar de notar las importantes diferencias que se aprecian entre las distintas provincias recogidas en el cuadro. Así, mientras en Asturias uno de cada tres expedientados resultó sancionado, en Sevilla, Huesca o Granada lo fue (en números redondos) uno de cada seis. Asturias, Barcelona, Vizcaya, Girona y Madrid, por ese orden, fueron las provincias donde la depuración arrojó un balance más negativo para los maestros. En el otro extremo se sitúan las citadas Sevilla, Huesca y Granada.

La razón de estas diferencias hay que buscarla, más que en la actuación de la comisión depuradora provincial (que, obviamente, también pudo influir) en la situación política y social de cada una de las provincias durante la etapa republicana, incluyendo la guerra civil. Así, el Magisterio asturiano pagó la desaforada campaña que la prensa derechista y católica desencadenó contra los maestros tras la revolución de $1934^{50}$, la mayor dureza de la represión en Madrid y Barcelona se explica por la importancia política de las respectivas capitales, por el hecho de ser la sede de los principales organismos de la administración educativa y, evidentemente, por tratarse de zonas con un más avanzado proceso de secularización y modernización social; en Girona y Vizcaya, en fin, la cuestión nacional catalana y vasca, respectivamente, desempeña un papel fundamental a la hora de explicar la intensidad de la depuración. El caso de Vizcaya merece un comentario especial: por el porcentaje de sancionados ocupa el tercer puesto entre las 17 provincias estudiadas; pero si se analizan exclusivamente las separaciones del servicio, baja rápidamente puestos en la clasificación, hasta situarse, en ese apartado concreto, claramente por debajo de la media del conjunto. Lo que hizo de Vizcaya una de las provincias con más sancionados, en términos relativos, fue el altísimo porcentaje de traslados forzosos, lo que, como se verá, tiene mucho que ver con las acusaciones relacionadas con cuestiones nacionalistas.

\footnotetext{
49 La bibliografía sobre el Magisterio durante la Segunda República es amplia. En relación con los aspectos señalados, véanse especialmente: NAVARRO, Ramón, L'educació a Catalunya durant la Generalitat 1931-1939, Barcelona 1979; ORTEGA BERENGUER, Emilio, La enseñanza pública en la II República, Málaga 1931, Málaga 1982; BENVENUTY MORALES, Juan, Educación y política educativa en Cádiz durante la Segunda República (1931-1936). Análisis de la reforma, Cádiz 1987; CID FERNÁNDEZ, Xosé Manuel, op. cit.; PALMERo CÁMARA, $\mathrm{M}^{\mathrm{a}}$ del Carmen, Educación y sociedad en la Rioja republicana (1931-1936), Salamanca 1990; BORQUE LÓPEZ, Leonardo, El magisterio primario en Asturias (19231937). Sociedad y educación, Gijón 1991; y RuIz RODRIGO, Cándido, Política y educación en la II República (Valencia 1931-1936), Valencia 1993.

so Véase BORQUE LóPEZ, Leonardo, op. cit., págs. 201-208.
}

Hispania, LXI/2, núm. 208 (2001) 661-688 


\begin{tabular}{|c|c|c|c|c|c|c|c|c|c|c|c|c|c|c|c|c|c|c|}
\hline \multirow{2}{*}{ RESOLUCIONES } & \multirow{2}{*}{$\begin{array}{l}\text { Total en } \\
\text { las } 17 \\
\text { provin- } \\
\text { cias }\end{array}$} & \multicolumn{17}{|c|}{ PROVINCIAS } \\
\hline & & $\begin{array}{l}\text { Alba- } \\
\text { cete }\end{array}$ & $\begin{array}{c}\text { Astu- } \\
\text { rias }\end{array}$ & $\begin{array}{c}\text { Barce- } \\
\text { lona }\end{array}$ & Burgos & Girona & $\begin{array}{l}\text { Gra- } \\
\text { nada }\end{array}$ & $\begin{array}{c}\text { Gui- } \\
\text { puzcoa }\end{array}$ & Huesca & Lleida & Madrid & Murcia & Navarra & $\begin{array}{c}\text { Ponte- } \\
\text { vedra }\end{array}$ & Sevilla & $\begin{array}{c}\text { Tarra- } \\
\text { gona }\end{array}$ & $\begin{array}{c}\text { Valen- } \\
\text { cia }\end{array}$ & Vizcaya \\
\hline $\begin{array}{l}\text { Confirmación en el } \\
\text { cargo/en sus derechos }\end{array}$ & $\begin{array}{l}17.492 \\
(74,03)\end{array}$ & $\begin{array}{r}452 \\
(73,14)\end{array}$ & $\begin{array}{r}1.542 \\
(66,64)\end{array}$ & \begin{tabular}{|r|}
1.630 \\
$(69,21)$
\end{tabular} & $\begin{array}{r}1.298 \\
(74,30)\end{array}$ & $\begin{array}{r}768 \\
(71,78)\end{array}$ & \begin{tabular}{|r|}
1.015 \\
$(82,59)$ \\
\end{tabular} & $\begin{array}{r}337 \\
(74,72)\end{array}$ & $\begin{array}{r}826 \\
(85,60)\end{array}$ & $\begin{array}{r}775 \\
(76,73)\end{array}$ & $\begin{array}{r}1.874 \\
(72,16)\end{array} \mid$ & $\begin{array}{r}719 \\
(75,53)\end{array}$ & $\begin{array}{r}883 \\
(75,41)\end{array}$ & $\begin{array}{r}1.104 \\
(74,70)\end{array} \mid$ & $\begin{array}{r}1.001 \\
(86,89)\end{array}$ & $\begin{array}{r}804 \\
(77,98)\end{array}$ & $\begin{array}{r}1.763 \\
(72,01)\end{array}$ & $\begin{array}{r}701 \\
(70,17)\end{array}$ \\
\hline $\begin{array}{l}\text { Separación/Inhabilitación } \\
\text { absoluta/Pérdida de } \\
\text { todos los derechos } \\
\text { adquiridos }\end{array}$ & $\begin{array}{l}2.284 \\
(9,67)\end{array}$ & $\begin{array}{r}46 \\
(7,44)\end{array}$ & $\begin{array}{r}385 \\
(16,64)\end{array}$ & $\begin{array}{r}364 \\
(15,46)\end{array}$ & $\begin{array}{r}136 \\
(7,78)\end{array}$ & $\begin{array}{r}119 \\
(11,12)\end{array}$ & $\begin{array}{r}101 \\
(8,21)\end{array}$ & $\begin{array}{r}51 \\
(11,31)\end{array}$ & $\begin{array}{r}39 \\
(4,04)\end{array}$ & $\begin{array}{r}47 \\
(4,65)\end{array}$ & $\begin{array}{r}365 \\
(14,05)\end{array} \mid$ & $\begin{array}{r}62 \\
(6,51)\end{array}$ & $\begin{array}{r}79 \\
(6,75)\end{array}$ & $\begin{array}{r}90 \\
(6,09)\end{array}$ & $\begin{array}{r}41 \\
(3,56)\end{array}$ & $\begin{array}{r}87 \\
(8,44)\end{array}$ & $\begin{array}{r}195 \\
(7,96)\end{array}$ & $\begin{array}{r}77 \\
(7,71)\end{array}$ \\
\hline $\begin{array}{l}\text { Suspensión o inhabili- } \\
\text { tación temporal }(* *)\end{array}$ & $\begin{array}{l}1.211 \\
(5,13)\end{array}$ & $\begin{array}{r}49 \\
(7,93)\end{array}$ & $\begin{array}{r}188 \\
(8,12)\end{array}$ & $\begin{array}{r}47 \\
(1,99)\end{array}$ & $\begin{array}{r}81 \\
(4,63)\end{array}$ & $\begin{array}{r}32 \\
(2,99)\end{array}$ & $\begin{array}{r}36 \\
(2,93)\end{array}$ & $\begin{array}{r}23 \\
(5,10)\end{array}$ & $\begin{array}{r}55 \\
(5,70)\end{array}$ & $\begin{array}{r}77 \\
(7,62) \\
\end{array}$ & $\begin{array}{r}81 \\
(3,12)\end{array}$ & $\begin{array}{r}55 \\
(5,78)\end{array}$ & $\begin{array}{r}122 \\
(10,42)\end{array}$ & $\begin{array}{r}173 \\
(11,70)\end{array}$ & $\begin{array}{r}60 \\
(5,20)\end{array}$ & \begin{tabular}{|r|}
66 \\
$(6,40)$
\end{tabular} & $\begin{array}{r}55 \\
(2,23)\end{array}$ & $\begin{array}{r}11 \\
(1,10)\end{array}$ \\
\hline $\begin{array}{l}\text { Traslado de } \\
\text { localidad }(* *)\end{array}$ & $\begin{array}{l}2.273 \\
(9,62)\end{array}$ & $\begin{array}{r}80 \\
(12,95)\end{array}$ & $\begin{array}{r}290 \\
(12,53) \\
\end{array}$ & $\begin{array}{r}259 \\
(11,00)\end{array}$ & $\begin{array}{r}139 \\
(7,95)\end{array}$ & $\begin{array}{r}75 \\
(7,00)\end{array}$ & $\begin{array}{r}63 \\
(5,12) \\
\end{array}$ & $\begin{array}{r}56 \\
(12,42)\end{array}$ & $\begin{array}{r}58 \\
(6,01)\end{array}$ & $\begin{array}{r}103 \\
(10,20)\end{array}$ & $\begin{array}{r}208 \\
(8,01)\end{array}$ & $\begin{array}{r}64 \\
(6,72) \\
\end{array}$ & $\begin{array}{r}68 \\
(5,81) \\
\end{array}$ & $\begin{array}{r}225 \\
(15,22) \\
\end{array}$ & $\begin{array}{r}78 \\
(6,77)\end{array}$ & $\begin{array}{r}96 \\
(9,31)\end{array}$ & $\begin{array}{r}259 \\
(10,57)\end{array}$ & $\begin{array}{r}152 \\
(15,21)\end{array}$ \\
\hline $\begin{array}{l}\text { Inhabilitación para cargos } \\
\text { directivos }\end{array}$ & $\begin{array}{r}709 \\
(3,00)\end{array}$ & $\begin{array}{r}23 \\
(3,72)\end{array}$ & $\begin{array}{r}62 \\
(2,68)\end{array}$ & $\begin{array}{r}50 \\
(2,12)\end{array}$ & $\begin{array}{r}4 \\
(0,23)\end{array}$ & $\begin{array}{r}84 \\
(7,85) \\
\end{array}$ & $\begin{array}{r}40 \\
(3,25) \\
\end{array}$ & $\begin{array}{r}4 \\
(0,89)\end{array}$ & $\begin{array}{r}17 \\
(1,76)\end{array}$ & \begin{tabular}{|r|}
20 \\
$(1,98)$ \\
\end{tabular} & $\begin{array}{r}114 \\
(4,39)\end{array}$ & $\begin{array}{r}52 \\
(5,46) \\
\end{array}$ & - & $\begin{array}{r}1 \\
(0,07)\end{array}$ & $\begin{array}{r}8 \\
(0,69)\end{array}$ & \begin{tabular}{|r|}
28 \\
$(2,72)$
\end{tabular} & $\begin{array}{r}135 \\
(5,51)\end{array}$ & $\begin{array}{r}67 \\
(6,71)\end{array}$ \\
\hline Otras & $\begin{array}{r}318 \\
(1,35)\end{array}$ & $\begin{array}{r}4 \\
(0,64)\end{array}$ & $\begin{array}{r}1 \\
(0,04)\end{array}$ & $\left|\begin{array}{r}* * * 43 \\
(1,82)\end{array}\right|$ & $\begin{array}{r}* * * * 113 \\
(6,46)\end{array}$ & $\begin{array}{r}5 \\
(0,47)\end{array}$ & $\begin{array}{r}5 \\
(0,41) \\
\end{array}$ & - & $\begin{array}{r}4 \\
(0,41) \\
\end{array}$ & $\begin{array}{r}16 \\
(1,58) \\
\end{array}$ & $\begin{array}{r}13 \\
(0,50) \\
\end{array}$ & - & $\begin{array}{r}* * * 55 \\
(4,70)\end{array}$ & $\begin{array}{r}3 \\
(0,21) \\
\end{array}$ & $\begin{array}{r}15 \\
(1,30)\end{array}$ & $\begin{array}{r}3 \\
(0,29) \\
\end{array}$ & \begin{tabular}{|l|}
$* * * 40$ \\
$(1,63)$ \\
\end{tabular} & $\begin{array}{r}1 \\
(0,10)\end{array}$ \\
\hline TOTAL EXPEDIENTES & 23.627 & 618 & 2.314 & 2.355 & 1.747 & 1.070 & 1.229 & 451 & 965 & 1.010 & 2.597 & 952 & 1.171 & 1.478 & 1.152 & 1.031 & 2.448 & 999 \\
\hline
\end{tabular}

* Los datos se expresan en cifras absolutas y (entre paréntesis) en porcentajes calculados sobre el total de expedientes censados de cada provincia.

** Los sancionados con suspensión y traslado de localidad aparecen contabilizados dos veces (una en cada apartado), por lo que la suma de los distintos apartados de cada columna no coincide con el total de expedientes de la provincia; en Valencia, sin embargo, aparecen incluidos sólo en el apartado de traslado de localidad, sin que los autores del estudio que sirve de fuente especifiquen cuántos de esos traslados llevaban aparejada, además, la sanción de suspensión temporal de empleo y sueldo.

*** Incluye 33 sanciones desconocidas en Barcelona, 92 en Burgos, 48 en Navarra y 37 en Valencia.

Fuentes: Elaboración propia a partir de BERRUEZO ALBÉNIZ, Reyes, op. cit., págs. 153-156 (para la provincia de Navarra); CRESPo REDONDO, Jesús et al., op. cit., pp. 171-173 y 177-179 (para la provincia de Burgos); FernáNDeZ SORIA, Juan Manuel y AGUlió DíAZ, Mª del Carmen, Maestros valencianos..., op. cit., pág. 209 (para la provincia de Valencia); JIMÉNEZ MADRID, Ramón, op. cit, págs. 119-152 (para la provincia de Murcia); MORENTE VALERO, Francisco, La escuela y el Estado Nuevo..., op. cit., pág. 346 (para las provincias de Albacete, Asturias, Barcelona, Girona, Granada, Huesca, Lleida, Madrid, Pontevedra, Sevilla, Tarragona y Vizcaya); y OstolAZA EsNAL, Maitane, op. cit., pág. 139 (para la provincia de Guipúzcoa). 
El análisis desglosado del cuadro ofrece otras informaciones de interés. Así, aproximadamente uno de cada diez expedientados fue separado definitivamente del servicio y/o inhabilitado de forma absoluta para la enseñanza. También aquí las diferencias provinciales son notables, aunque por regla general allí donde hubo un mayor porcentaje de sancionados, el porcentaje de separaciones fue también más alto; la excepción ya comentada fue Vizcaya. Por lo que hace a las suspensiones temporales de empleo y sueldo, afectaron a uno de cada veinte expedientados, es decir, se dieron con menor frecuencia que las separciones del servicio. Esta aparente paradoja se explica con relativa facilidad: a lo largo del proceso depurador, las autoridades educativas centrales fueron encontrándose con serios problemas de personal disponible (como consecuencia de la propia depuración, pero también de otros efectos de la guerra: muertos, encarcelados, huidos, movilizados...), lo que llevó a aplicar la sanción de suspensión de empleo exclusivamente en los casos considerados muy graves (aunque no tanto como para merecer la expulsión definitiva), prefiriéndose en los demás casos otras sanciones alternativas que permitiesen contar con los servicios del maestro sancionado. Es ésta una cuestión importante sobre la que habrá que volver nuevamente al valorar otros aspectos del resultado final de la depuración.

Entre las sanciones que podían resultar muy duras pero que permitían al maestro continuar trabajando, los traslados forzosos eran sin duda la mejor alternativa. Ello explica que su porcentaje de aplicación fuera muy alto, casi equiparable a las separaciones definitivas. El traslado forzoso permitía conjugar dureza represiva y necesidad de personal docente, pero además era la respuesta adecuada para conductas que las comisiones consideraban menos graves, así como para resolver los expedientes en que la acusación fundamental tuviese relación con las ideas o actividades nacionalistas. Así se explica que sea precisamente en aquellas provincias donde la cuestión nacional podía tener importancia, donde, con diferencia, se dan los más altos porcentajes de traslados forzosos (Pontevedra, Vizcaya, Guipúzcoa, Barcelona y Lleida superan el 10\%); las únicas excepciones a esta regla las constituyen Albacete y Asturias. En los expedientes con cargos relativos al nacionalismo y que se sustanciaban con traslado, éste era indefectiblemente «fuera de la región» (en ocasiones se añadía, «y de las provincias limítrofes»), pues se trataba de colocar al maestro en cuestión en un ambiente en el que sus ideas nacionalistas no encontrasen terreno propicio para su difusión (no ha de extrañar, por tanto, que la sanción de traslado fuera de la región no aparezca más que en las provincias catalanas, gallegas y vascas) ${ }^{51}$

s1 Véase, Morente VAlero, Francisco: La escuela y el Estado Nuevo..., op. cit., pág. 348. Lo anterior no quiere decir que en otras partes no se trasladara a los maestros a provincias lejanas; de hecho, el estudio de la documentación disponible muestra cómo, por regla general, la sanción de «traslado fuera de la provincia» significaba casi siempre el traslado a provincias muy distantes de la de origen. 
Finalmente, por lo que hace a la inhabilitación para cargos directivos y de confianza, se ha de señalar que, además de a quienes se les aplicó dicha sanción en exclusiva (que son los casos reflejados en el cuadro I), hay que contar con quienes recibieron sanciones más graves (como suspensiones y traslados) y que, habitualmente, llevaban aparejada la accesoria de inhabilitación para cargos. Esta sanción era aparentemente benévola, pero tenía efectos a muy largo plazo, afectando a la promoción profesional del interesado, al tiempo que impedía que personas no consideradas completamente adictas al régimen pudieran acceder a puestos de responsabilidad en la administración y los centros educativos.

Antes de pasar a considerar la cuestión de las cifras globales de la depuración, conviene hacer una rápida reflexión sobre la relación que se dio entre el trabajo de las comisiones provinciales y el de las instancias del MEN que supervisaron el trabajo de aquéllas. En términos generales, el Ministerio modificó de forma bastante sustancial muchas de las propuestas de resolución que le llegaban desde las comisiones provinciales. Sin embargo, esa rectificación del trabajo de las comisiones no fue tanto una descalificación de las mismas cuanto el resultado de una diferente valoración de la situación en que se encontraba la situación de la enseñanza pública durante el proceso depurador. Por ello, las modificaciones que llevaron a cabo las instancias ministeriales respondían no sólo a un análisis diferente de los elementos contenidos en el expediente de depuración, sino, sobre todo, a la aplicación de una serie de criterios generales derivados de la angustiosa falta de personal docente a la que aludíamos más arriba. Por ese motivo, contempladas en su conjunto y al margen del análisis de casos concretos, las resoluciones dictadas por el MEN que rectificaban las propuestas de resolución emanadas de las comisiones provinciales tendieron a suavizar el resultado global de la depuración. Y eso fue así en todas las provincias hasta ahora estudiadas, sin excepción. Por regla general, las propuestas de confirmación en el cargo eran sistemáticamente ratificadas por el Ministerio ${ }^{52}$, se disminuían en la medida de lo posible las separaciones definitivas y las suspensiones temporales, y se incrementaban los traslados y otras sanciones. El

52 Sobre una muestra de 772 expedientes de depuración correspondientes a 12 provincias diferentes, y con propuesta de confirmación en el cargo, el Ministerio ratificó 768, sancionó en 3 casos, y en otro más no se ha podido establecer cuál fue el resultado definitivo del expediente; Ibid., pág. 362. Ateniéndonos a la práctica infalibilidad de esta regla, podrían darse datos más completos sobre la depuración de Murcia que los que figuran en el cuadro I. En efecto, Ramón Jiménez incluye en su estudio 246 expedientes cuya resolución final desconoce, pese a tener constancia de la propuesta de la comisión depuradora; de ellos, 226 tenían propuesta de confirmación, y 20 de sanción $(9$ separaciones, 2 suspensiones, 2 traslados, 5 inhabilitaciones para cargos y 2 postergaciones en el escalafón); también se da noticia de otros 23 casos de los que se desconoce tanto la propuesta como la resolución definitiva. Teniendo en cuenta los criterios del Ministerio, podrían contabilizarse casi con toda seguridad las 226 confirmaciones en el cargo como definitivas, mientras que las sanciones no superarían en ningún caso, antes al contrario, las 20. Con estos datos, la depuración en Murcia resultaría sensiblemente suavizada en relación a las cifras sobre las que hay constancia definitiva; véase JIMÉNEZ MADRID, Ramón, op. cit., págs. 119-152.

Hispania, LXI/2, núm. 208 (2001) 661-688 
incremento de los traslados no era sino el resultado de la suavización de sanciones más graves y que dejaban fuera del servicio, temporal o definitivamente, a los maestros. No se ha de deducir de todo ello que el Ministerio adoptase una posición menos rigurosa que la de las comisiones; sencillamente lo que se produjo fue una adecuación de la acción depuradora a las circunstancias imperantes. Las comisiones hicieron su trabajo, aplicando de forma bastante estricta la legislación elaborada por el Ministerio; fue éste el que tuvo que rebajar su exigencia inicial agobiado por la falta de personal docente. Ello no implicó tampoco que se dejasen de sancionar las conductas que se consideraban punibles en la normativa; lo que se hizo fue aplicar con criterio amplio el abanico sancionador, reservando la separación del servicio y las suspensiones de larga duración para aquellos maestros considerados irrecuperables, mientras que se utilizaban de inmediato los servicios de los demás reubicándolos en lugares donde su actuación pudiese estar más controlada y sus efectos fuesen menos dañinos.

Esta actuación dulcificadora del Ministerio ha sido señalada por todos los autores que se han ocupado de la cuestión, con la excepción de M. Ostolaza quien considera que, en el caso de Guipúzcoa, las resoluciones definitivas del Ministerio supusieron un «endurecimiento general de las sanciones» ${ }^{53}$. Sin embargo, de los datos que la propia autora maneja, creo que no puede derivarse esa conclusión. Veamos. Tras la intervención del Ministerio, los expedientes con sanción pasaron de 119 a 121 . Ahora bien, hay que calibrar en qué medida se modificaron los distintos tipos de sanción. Así, las destituciones bajaron de 67 a 62, mientras que las suspensiones con traslado fuera de la región pasaron de 3 a 6 , y los traslados fuera de la región de 10 a $16^{54}$. Es decir, las sanciones graves propuestas aumentaron en nueve casos una vez intervino el Ministerio, pero con certeza cinco eran el resultado de la rectificación de sendas separaciones del servicio, lo que deja en cuatro expedientes los casos en que realmente se endureció la propuesta de sanción (sin llegar a la separación del servicio), frente a cinco en que la sanción más grave posible se vio rectificada en sentido favorable a los docentes afectados. Sin duda estamos ante una suavización, bien que no espectacular, de las propuestas de la comisión, lo que no hacía sino iniciar una tendencia que se acentuó posteriormente, como en las demás provincias, durante el largo proceso de revisiones que siguió a la depuración propiamente dicha.

La extrapolación al conjunto del Magisterio español de los datos del cuadro I arrojaría los siguientes resultados del proceso depurador: en torno a una cuarta parte de sancionados, esto es, entre quince mil y dieciseis mil maestros; de ellos, alrededor de seis mil (es decir, un 10\% del total de expedientados) fueron separados definitivamente de la enseñanza; otros tantos perdieron su plaza y fueron trasladados forzosamente a localidades más o menos lejanas de las de origen; en torno a tres mil (un 5\% del total) padecieron una suspensión tempo-

53 OstolaZa ESNAL, Maitane: $o p$. cit., pág. 135.

54 Ibid., págs. 135-136. 
ral de empleo y sueldo de entre un mes y dos años de duración (hay que recordar que muchos sufrieron la suspensión y el traslado de forma acumulativa); casi dos mil fueron inhabilitados para ejercer cargos directivos (a los que hay que añadir quienes recibieron esa sanción como accesoria de otra más grave, es decir, prácticamente todos los sancionados con suspensión y/o traslado); finalmente otros mil docentes recibieron otras sanciones (jubilaciones forzosas, postergación en el escalafón, expedientes de disciplina - en el caso de alumnos de magisterio-, etc.). En todas las provincias, los maestros resultaron mucho más castigados (y más duramente) que las maestras, tanto en términos absolutos como relativos. Las maestras se beneficiaron de una actitud paternalista tanto de las comisiones como de las autoridades ministeriales, que las consideraban influenciables y con escasas luces, lo que las hacía a sus ojos menos responsables que sus compañeros varones.

Pese a que en el momento de crearse las comisiones depuradoras, en 1936, la normativa había establecido un plazo de tres meses para completar todo el proceso, el grueso de la depuración no estuvo terminado hasta 1942, y después de ese año se produjo un goteo incesante de nuevos expedientes que se prolongó hasta bien entrados los años cincuenta. Paralelamente se desarrolló un proceso de revisión de expedientes de depuración que duró hasta finales de los años sesenta. La revisión del expediente se podía producir de oficio (por ejemplo, si el Ministerio tenía noticia de alguna sanción impuesta en consejo de guerra o como consecuencia de un expediente de responsabilidades políticas), o bien, lo que era más frecuente, a iniciativa de la parte afectada. La petición de revisión no siempre era aceptada, pues se habían de alegar nuevos elementos de juicio de la suficiente importancia como para considerar una modificación en la resolución que había recaído en el expediente. Sólo una parte de los expedientes que finalizaron con sanción se beneficiaron de un posterior proceso de revisión ${ }^{55}$. El resultado del mismo supuso una nueva suavización de los efectos iniciales de la depuración ${ }^{56}$; sin embargo, no hay que magnificar este hecho; en primer lugar porque fueron mayoría los expedientes no revisados; después, porque el proceso de revisión acostumbraba a ser extremadamente largo, por lo que en muchos casos, una resolución favorable no pasaba de tener efectos puramente testimoniales (por ejemplo, en el caso de sanciones de traslado de loca-

55 En el Archivo Central del Ministerio de Educación se conservan poco más de 6.000 expedientes de revisión tramitados entre 1939 y 1969, lo que significaría que algo más de un tercio de los maestros sancionados solicitaron la revisión de su expediente; entre estos expedientes están también los revisados de oficio.

s6 Sobre una muestra de 1.194 expedientes de revisión correspondientes a 14 provincias y tramitados hasta 1943 , en el $34,5 \%$ de los casos la resolución inicial del expediente no se modificó, en un $4,3 \%$ de los expedientes se produjo un agravamiento de la misma (por lo general, eran los expedientes tramitados de oficio), y en un $59 \%$ hubo una suavización de la sanción impuesta en un primer momento; en el 2,2\% restante no ha sido posible conocer el resultado final de la revisión; véase MORENTE VALERO, Francisco: La escuela y el Estado Nuevo...op. cit., pág. 373.

Hispania, LXI/2, núm. 208 (2001) 661-688 
lidad, o de suspensión temporal de empleo); además, era poco frecuente que de la revisión se derivase una completa absolución del interesado; lo habitual era que se mantuviese algún tipo de sanción, si bien de grado inferior a la recibida en el primer expediente.

De todo lo anterior no cabe deducir que el régimen hubiese renunciado a su intención de castigar las conductas consideradas incompatibles con el Nuevo Estado; la relativa suavización de la depuración inicial se explica, por contra, a partir de al menos tres factores: la ya citada necesidad de personal docente, el giro estratégico iniciado a medida que la guerra mundial cambiaba de rumbo en perjuicio del Eje, y la evidencia de que gran parte de los expedientes estaban construidos sobre bases documentales tan débiles y vergonzosas que difícilmente permitían mantener flagrantes injusticias una vez se habían superado los tiempos de mayor exaltación represiva.

\section{La depuración y la escuela franquista}

Las cifras, con ser importantes, no lo son todo, ni mucho menos. Detrás de los números que reflejan la intensidad de la depuración del Magisterio se esconden muchos dramas que son difícilmente reproducibles en lo que de dolor, incertidumbre, miedo y rabia tuvieron para sus protagonistas. $Y$ junto a estos efectos puramente personales, hay que considerar los que se derivaron para el sistema educativo español en su conjunto. La labor de destrucción de la obra escolar republicana ha sido ampliamente estudiada ${ }^{57}$, y no es necesario reproducirla aquí por extenso. No se puede olvidar, sin embargo, la importancia que la depuración del Magisterio tuvo como instrumento de esa obra de derribo. Como es bien sabido, la reforma educativa republicana tuvo diversas líneas de actuación: las mejoras materiales (tanto de las infraestructuras escolares como de los sueldos de los docentes), la democratización de las estructuras educativas, la actualización de materias y contenidos, y la renovación pedagógica (vinculada de forma muy directa con la formación y selección del nuevo profesorado, así como con el reciclaje profesional del que ya ejercía anteriormente). Todos estos aspectos fueron profundamente removidos por la contrarreforma educativa que emprendieron las autoridades franquistas desde el inicio mismo de la guerra civil, y la depuración del profesorado fue la palanca necesaria para liquidar los avances que los gobiernos republicanos habían realizado en el último de los aspectos que han sido relacionados.

\footnotetext{
57 Véanse, especialmente, MonÉs, Jordi: L'escola a Catalunya sota el franquisme, Barcelona 1981; NAVARRo SANDALINAS, Ramón: La enseñanza primaria durante el franquismo (1936-1975), Barcelona 1990; MAYORDOMO PÉREZ Alejandro y Juan Manuel FernáNDEZ SORIA, Vencer y convencer. Educación y política. España 1936-1945, Valencia 1993; y FeRNÁNDEZ SORIA, Juan Manuel: Educación, socialización y legitimación política (España 1931-1970), Valencia 1998.
} 
Mediante la purga del profesorado, se separó de la enseñanza a quienes más se habían distinguido en el apoyo y puesta en práctica de las reformas republicanas. La depuración se cebó por una parte en quienes habían mostrado un mayor compromiso, ideológico y práctico, con la experiencia republicana. Así, la militancia y la ideología izquierdistas fueron las acusaciones que llevaban aparejadas las sanciones más duras ${ }^{58}$, pero igualmente fueron objeto de enérgica sanción determinados cargos relacionados con la orientación pedagógica de los docentes, de forma que quienes habían destacado en el afán innovador, en la aplicación de las directrices de la llamada escuela nueva, o, sencillamente, en la introducción en España de las corrientes pedagógicas más innovadoras del momento eran, cuando menos, apartados de cualquier posición de influencia dentro del aparato educativo.

El exilio de los docentes más significados políticamente, la separación del servicio de quienes, siéndolo también, intentaron superar el trámite depurador, el traslado a pequeñas localidades de provincias remotas de otros, y, en cualquier caso, el desplazamiento de cualquier cargo de responsabilidad en la estructura educativa de aquéllos cuya conducta e ideas no fueron consideradas absolutamente acordes con el nuevo estado de cosas generó un insuperable empobrecimiento del personal docente en la escuela pública. El vacío dejado por los maestros expulsados fue ocupado por quienes, alegando méritos patrióticos, se beneficiaron de un indisimulado reparto del botín de guerra: excombatientes, ex-cautivos, ex-oficiales del ejército (y sus respectivos familiares) ocuparon por miles puestos en la enseñanza pública, primero como interinos y luego como funcionarios tras oposiciones y concursos diseñados expresamente para ellos. En definitva, la destrucción de la elite pedagógica del país, junto con la reordenación legal del sistema educativo, su ocupación por adictos al régimen y la vuelta a la tradición escolar más rancia sumieron a la enseñanza, en todos sus niveles, en un pozo del que tardaría décadas en volver a salir.

58 Para un análisis de la relación entre las acusaciones presentes en los expedientes de depuración y las sanciones que les correspondían, véase MORENTE VALERO, Francisco, La escuela y el Estado Nuevo...op. cit., págs. 336-345. En síntesis pueden establecerse las siguientes conclusiones al respecto: los actos concretos se penalizaban más duramente que las simples posiciones ideológicas; el izquierdismo (con sus diferentes matices) era el cargo más grave entre los de tipo político; también lo era cualquiera relacionado con el nacionalismo (catalán, vasco, gallego), si bien estos cargos, si no iban acompañados de otros, no solían provocar la expulsión del Magisterio, sino el traslado a provincias donde tales ideas no encontrasen terreno adecuado para germinar. La irreligiosidad en cualquiera de sus grados era duramente sancionada (en los más extremos —ateísmo, actos contrarios a la Iglesia...- con la separación del servicio), así como la pertenencia a la masonería. Por lo que hace a las conductas privadas, las relacionadas con el matrimonio (no haberse casado por la Iglesia, haberse divorciado, tener hijos sin estar casado...) y, sobre todo en el caso de las mujeres, la sexualidad eran objeto de riguroso escrutinio y, en su caso, sanción.

Hispania, LXI/2, núm. 208 (2001) 661-688 